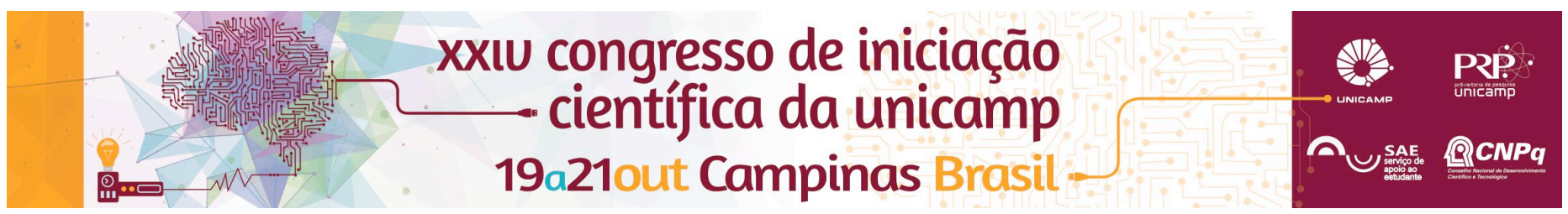

\title{
Análise comparativa de modelos de dimensionamento de pátios em aeroportos
}

\author{
Rafael Ken Nakano Ohira*, Carlos Alberto Bandeira Guimarães
}

\section{Resumo}

Este trabalho teve como meta realizar uma análise comparativa entre métodos de dimensionamento de um terminal aeroviário. Serão analisados os resultados obtidos através de um modelo analítico e de um modelo computacional. Alguns dados importantes de aeroportos foram coletados para que fosse possível aplicar os métodos de dimensionamento, e posteriormente, haverá a comparação dos resultados obtidos.

\section{Palavras-chave:}

Dimensionamento de aeroportos, pátios aeroportuários, capacidade do pátio.

\section{Introdução}

Recentemente, houve um crescimento bastante acelerado no movimento dos aeroportos brasileiros. A situação aeroportuária no país tem chamado bastante atenção pelo número de crises que vem passando, assim como problemas em relação a atrasos, aeroportos lotados e a incapacidade de atender à demanda atual de passageiros. O fluxo intenso de aeronaves nos terminais exige uma organização e uma estrutura impecável, porém é notável que os pátios não acompanharam a crescente movimentação em termos de pousos e decolagens. Tal crescimento provocou inúmeros problemas, por isso, há uma necessidade de propor soluções que atendam a atual demanda do sistema aeroviário do país. Tendo conhecimento dos modelos de dimensionamento e dos dados necessários, é possível analisar e comparar qual modelo é mais eficiente e, finalmente, propor soluções que possam ser empreendidas para que a infraestrutura do transporte aéreo atenda à atual demanda dos aeroportos do país.

A pesquisa teve como objetivo comparar modelos de dimensionamento de terminais em aeroportos. Além de levantamento bibliográfico, foi feita uma análise crítica dos resultados, comparando os diferentes métodos levantados, suas vantagens e desvantagens.

\section{Resultados e Discussão}

Foram coletados dados referente a um dia qualquer de todos os vôos dos principais aeroportos brasileiros. A classe da aeronave, a origem, o destino, o número do vôo, a companhia aérea e o terminal de embarque são os itens que foram estudados. Assim, foi possível analisar a movimentação das aeronaves e obter o tempo de ocupação da mesma no pátio. Esse tempo obtido será fundamental para a etapa final do trabalho que consistirá no dimensionamento do pátio aeroportuário através de dois métodos: computacional e analítico.

\section{Conclusões}

As etapas referentes à conclusão ainda não foram terminadas. Os dados necessários já foram obtidos e analisados, porém ainda não foram utilizados para o dimensionamento dos pátios aeroportuários.

\section{Agradecimentos}

Agradaço ao meu orientador Carlos Alberto B. Guimarães pelos ensinamentos e pela oportunidade de estar realizando esta inicação científica. Aproveito para agradecer meus pais Akio e Elza e minha irmã Vanessa por todo apoio, que sem dúvida, foi fundamental para que eu tivesse total condições de ingressar na Universidade Estadual de Campinas.

1. Horonjeff, R. ,McKelvey, F.X., Sproule, W.J. \& Young, S.B. Planning and Design of Airports. 5th. ed., McGraw-Hill, 2010.

2. 2. Ashford, N. \& Wright, P.H. Airport Enginnering. 4th.ed., John Wiley, 2011

3. Barros, A. G. \& Wirasinghe, S. C., New Aircraft Characteristics Related to Airport Planning. First ATRG Conference, Vancouver, Canada , June 25-27, 1997.

4. Agência Nacional de Aviação Civil - ANAC, Demanda na Hora de Pico - Aeroportos da Rede Infraero. la edição , Rio de Janeiro, 2007.

5. Transportation Research Board, ACRP - Report 25 - Airport Passenger Terminal Planning and Design, Volume 1: Guidebook. Washington, 2010

6. IATA - International Air Transport Association, Airport Development Reference Manual, 9th Edition, Montreal, 2004. 